\title{
Social Media and Trust - A Systematic Literature Review
}

\author{
Peter Håkansson, Hope Witmer \\ (Malmö University, 20506 Malmö, Sweden)
}

\begin{abstract}
The role of trust has long been acknowledged among economists and political scientists. It is often argued that high levels of trust among people help promote democratization, economic activity, well-performing institutions and low levels of violence. Social media has been identified as a significant vehicle in fostering social connections however the depth and significance of these connections to the creation of trust has not been well developed. According to Robert Putnam trust derives from reciprocity that is learned only in cooperation with others. Putnam is skeptical of a positive relationship between trust and digitalized social media. According to Uslaner trust is a moral issue established by family relationships early in life and therefore use of social media has no impact on creating trust. This paper is a structured literature review. The aim is to investigate if trust can be created by connections on digitalized social media. Eight articles emphasized a positive relationship between social media and trust; two articles claimed no relationship between trust and social media. We did not find any studies claiming there is a negative relation between social media and trust.
\end{abstract}

Key words: social media; trust; internet; digital communication

JEL codes: A12, A13, Z13

\section{Introduction}

Is it important to live in a society where people trust each other? Most people would probably answer "yes". They prefer to live in a society where people trust each other, rather than in a society where people distrust each other. Social trust and the negative impact of the decline of trust has been a rising concern among economists and political scientists. It is well documented that trust is a significant component of many relations, it can lower transaction costs and risk and that high levels of trust promote investment and growth (Knack \& Keefer, 1997; Putnam, 2000; Zak \& Knack, 2001; Uslaner, 2002). How trust actually is created has been more of an open discussion. According to Robert Putnam trust is derived from reciprocity that is created by participation in associations and other forms of voluntary organizations. According to Uslaner trust is something learned at a young age. However, both these points are well debated and the research on trust is expansive. Increased use of Internet technology raises new questions about the role of social media and if social media can be a vehicle for creating trust? The aim of this paper is to investigate the research on this issue. The focus is on if digitalized social media and the Internet can create generalized social trust. The method we use is a structured literature review.

Peter Håkansson, Ph.D. in Economic History, Postdoc, Center for Work Life and Evaluation Studies, Malmö University; research areas/interests: social capital, labor market entry, school-to-work transition. E-mail: peter.hakansson@mah.se.

Hope Witmer, Ph.D. in Applied Management and Decision Sciences, Department of Urban Studies, Leadership and Organization, Malmö University and Center for Work Life and Evaluation Studies, Malmö University; research areas/interests: organizational resilience, leadership, ethics and trust. E-mail: hope.witmer@mah.se. 
Kitchenham (2004) and Kitchenham et al. (2009) guidelines for a systematic literature review was used to identify, evaluate and interpret the available empirical studies on this topic.

\section{The Concept of Trust}

Trust between people, social trust, and specifically generalized trust, defined as trust between people in general and people who do not know each other that well, have been well debated at least since Robert Putnam published “Making Democracy Work” in 1993. According to Robert Putnam (1993, 2000) trust derives from reciprocity, which can be learned only in cooperation with others. From Putnam's perspective this means that trust is created in associations and other forms of voluntary organizations. Uslaner (2002), on the other hand, argues that people who join associations, so called "joiners", appear to be more trusting from the outset. If so, it is not the associational membership per se that explains their higher level of trust. Instead Uslaner suggests that trust has a moral dimension, a virtue that is learned in early years from the parents.

Rothstein (2003) takes another position. According to Rothstein trust does not exist independently of politics or government. He proposes that when people are faced with corruption within institutions and/or do not feel adequately protected; they will lose trust in institutions. This leads to people assuming that others are resorting to bribery and other forms of corruption to get ahead and as a result get preferential treatment. This in-turn leads them to question whether they can really trust others and as a result generalized trust will be eroded. This position infers that trust depends on good governance (Rothstein, 2003).

Can trust be created by networking on social media or does it have to be live meetings? Putnam doubted that the Internet and social media could create trust, but he had little evidence when he published "Bowling Alone" in 2000. The reason Putnam doubts the role of the Internet in creating trust is that it is time consuming and thereby prevents "live" face to face meetings and limits the interactions to people one already knows (Putnam, 2000). In support of this negative view on the use of the internet to build relationships are the reports of individuals that create false identifies on-line in order to lure vulnerable individuals into relationships that are not mutually beneficial and/or could be potentially harmful (Rheingold, 1993). Furthermore there is the recent concern of government and corporate Internet surveillance. Due to recent scandals in the United States that have exposed government internet surveillance there is concern that the level of surveillance will increase and that this will negatively impact trust associated with digital social media (Anderson \& Rainie, 2014). This could lead to the hypothesis that social media has a negative effect on trust.

In rebuttal, it could be argued that social media has a positive effect on trust. Digitalized social media communicates information much faster and much cheaper than live relationships. Information is a key issue when it comes to building and establishing trust. It is also easier and cheaper to find new relationships and to expand social markets on social media than in "the real world". Thus, our second hypothesis is that social media has a positive effect on trust.

Our third hypothesis is that social media has no effect on trust. According to Uslaner (2002), trust is a moral virtue that has little to do with if you are active in associations or on the Internet. Instead trust is learned at home, taught by your parents and depends on an optimistic worldview. In this case "the trusting" are active in associations and on the Internet because of an internal, established value. This makes a correlation between trust and use of the Internet, but does not indicate causality in the sense that it is the Internet that creates trust. 


\section{The Concept of Social Media}

Social media has been identified as a significant vehicle in fostering social connections that maintain or expand existing social networks (Ellison et al., 2007; Joinson, 2008). Different tools of social media create varying levels of connection between employees. For example global IT solution provider Dell Inc. found that the blog, the way it is used at Dell, facilitates the growth of cognitive social capital and that the micro-blog offers unique opportunities to increase structural social capital by facilitating the creation of ties among employees to a higher degree than the blog (Alex-Brown, 2011). Kline and Barker (2013) assert that developing communities of practice at places of employment through the vehicle of communication technologies results in a connection between employees that enhances collaboration and knowledge sharing within a company.

Social Media is used in many ways, for example email, checking the stock market, shopping and connecting with people. As the use of, and access to, social media continues to expand Facebook is still the dominant social network platform for adults. Youth ages (18-24) are using social media more heavily than previous generations (Duggan \& Smith, 2013). They have grown up with digitized media and have a need to stay constantly connected (Cabral, 2011; Oblinger \& Oblinger, 2005). This has created a new kind of peer relationship that is different than previous generations including a tendency to be more inclusive with whom they allow into their groups (Cabral, 2011).

\section{Literature Review - Method}

We have used a structured literature review model suggested by Kitchenham (2004) and Kitchenham et al. (2009). Malmö Universities comprehensive search tool Summon was used to identify relevant literature. The searches were conducted using the key words "social media" "trust" "social trust" "internet" in different combinations, as shown on Table 1. We limited the search to journals and to the disciplines political science, social science, psychology and sociology. This process excluded a number of articles, but also narrowed down an expansive search to the relevant content areas. From these articles we selected studies using the "title method" we excluded studies by reading the title and the first line after the title. In this phase and the coming sections in the review, the research question was in focus: Can social media create trust? The "title method" gave us 36 studies. We read the abstracts from these 36 studies, which resulted in excluding another 20 studies. In total 16 papers relevant to the research question were read. From the reference lists of these 16 studies, we identified 14 additional studies. In total, this gave us 30 papers to read. From these 30 papers we identified ten papers that were able to answer our research question "Can social media create trust?".

Table 1 Number of Findings in the Structured Literature Search

\begin{tabular}{|c|c|c|c|c|}
\hline Key words & "social media"“trust" & “social media”“social trust” & "social trust”“"internet” & Total \\
\hline Total find (just using key words) & 22022 & 376 & 3717 & \\
\hline Limitations: Journals & 6121 & 105 & 1037 & \\
\hline $\begin{array}{l}\text { Limitations: political science, social } \\
\text { science, psychology, sociology }\end{array}$ & 663 & 27 & 442 & \\
\hline Title method: First search & 26 & +2 & +8 & 36 \\
\hline Abstract method: First search-remaining & & & & 16 \\
\hline Second search: From ref. lists & & & & 14 \\
\hline Remaining after full paper read & & & & 10 \\
\hline
\end{tabular}




\section{Results}

We have sorted our results in three different categories that refer to our three hypotheses: Social media has a negative effect on trust, social media has a positive effect on trust or social media has no effect on trust.

Social media has a negative effect on trust: We have not found any studies that find a negative relationship between social media and trust, even though there may be rational explanations that it might exist. A possible explanation is that distrust is difficult to detect because it is a transient property in network relationships (Bian et al., 2009). There are also no accurate methods for measuring inferred distrust between social media users (DuBois, Golbeck \& Srinivasan, 2011). Another potential explanation is that people use social media as a way to control information and relationships and thereby mitigate uncertainty (Tidwell \& Walther, 2002) early on screening out any relationship that would have potential to breed distrust.

Social media has a positive effect on trust: Most of the studies we found show that social media has a positive effect on trust. Monforti \& Marichal (2014) studied digital skills and generalized trust in different ethnic groups: Latinos, African Americans and Anglo-Americans in the US. They found that digital skills were associated with generalized trust for African Americans but not for Latinos or Anglo-Americans. They used the survey 2010 PEW which asked questions on social media and computer use and skills, and ran the answers against answers on trust in a quantitative model. The statement used on trust is a common statement when it comes to measuring trust: "Most people can be trusted" versus "You can’t be too careful”. To measure digital skills they used two different indices on internet and digital use and skills (index 1) and cell phones and mobile wireless broadband (index 2). According to the authors the explanation for these results might be that internet can free African Americans from a social stigma that persists even for African Americans in high-status positions.

Jodi Liss (2011) describes a situation where a group of landowners were to negotiate a natural gas deal with an energy company. In these deals trust is of essential importance both within a group (collective bargaining) but also between parties. The problem addressed is asymmetric information. The landowners were in an information disadvantage towards the companies, but they also faced a problem of distrust between each other and a risk that someone defected. The Internet and social media gave landowners access to useful information and facilitated their ability to communicate with each other more easily and efficiently. According to Liss, to be able to share information builds trust, but it may also expand the deal beyond purely distributive financial considerations. In the case that Liss describes, the landowners set up a website where the members could privately log in and communicate with each other, and stay informed. The negotiators also sent out regular updates, relevant information and press clippings via e-mail. Later, another more locally specific website was set up.

Valenzuela, Park, and Kee (2009) conducted a random web survey of college students across Texas that examined if Facebook use is related to attitudes and behaviors that enhance individuals' social capital. They identified a positive relationship between intensity of Facebook use and college students' life satisfaction, social trust, civic engagement, and political participation. To measure social trust they used a web-based survey, that was a revision of Rosenberg's (1956) "Faith in people — scale" at two large public universities in the US. They found that intensity of Facebook use is positively associated with social trust. The contribution made by Facebook use to social trust was small but statistically significant. In the model of regressions predicting political participation, there was a positive, significant interaction between intensity of Facebook use and social trust. They suggest a possible explanation for this is that online social networks allow users to learn detailed information about their contacts, including personal background, interests, music tastes, and whereabouts. This information can reduce 
uncertainty about other users' intentions and behaviors, which is a necessary condition for developing norms of trust and reciprocity (Berger \& Calabrese, 1975). Furthermore, Facebook users typically form their network connections based on existing relationships of trust (Valenzuela, Park, \& Kee, 2009). These findings show the opposite of the more popular view that heavy Facebook users are more isolated and less connected than occasional users. This also contradicts the "time displacement hypothesis" that identified TV as the driving force behind the decline in social capital in the United States, this hypothesis started with the effects of television on social capital and was then expanded to the effects of the Internet on social capital. Putnam argued that T.V. viewing had privatized leisure time, thus inhibiting participation in activities outside the home (2000). Later this was refuted and found not to affect civic engagement (Norris, 1996; Uslaner, 1998).

Beaudoin (2008) also purports that Internet use influences interpersonal trust. Using data from PEW 2006 Internet and American life survey, structural equation modeling was used to test a multistep model of the influence of Internet use on the development of interpersonal trust. The mediating effect of social resource motivation and perceived information overload were measured for their influence on the development of interpersonal trust and Internet use. Beaudoin found that the greater the Internet use, the greater the interpersonal trust, when it is mediated by social resource motivation for Internet use. Social resource motivation is using media for the purpose of building or maintaining social resources, social contact and social interactions. He also found that the individuals with greater levels of perceived information overload had lower levels of interpersonal trust. Individuals assess the amount of information that they can process and control. If they feel overloaded by the amount of information this can result in termination of the source of information. If the source of information is social media, to eliminate feeling overloaded someone would discontinue the social media relationship thereby reducing the possibility of using social media to build trust. This research begins to identify mechanisms specific to digitized social media that contribute to or detract from the development of online social trust. Identifying precipitating mechanism- social resource motivation and information overload - to internet use and the impact on trust begins to unravel the complexity of this topic and offers a model for how to use existing data to identify underlying connections between the internet and trust. This has potential to open the door to studying trust in the context of existing theories to more specifically identify connections between the type of trust such as generalized, particularized or strategic and the type of relationship being developed through social media.

Best and Krueger (2006) tested the relationship between online users and social capital using a probability sample survey of U.S. residents. They conceptualized social capital as including the following elements, generalized trust, reciprocity and integrity. Contrary to previous empirical investigations they found that time spent with new online relations is a significant positive predictor of generalized trust. Although they could not verify that the Internet fosters deep connections and loyalty they did suggest that Internet interactions foster connections that can produce generalized trust. What is unique to their study is that they measured the degree of online interactions with those not known offline.

A study by Blanchard and Horan (1998) indicates that both geographically dispersed and physically based virtual communities may cause general increase in trust. This article's primary focus is on the role of virtual communities and social capital and the potential effects of virtual communities on networks, norms, trust and privatization of leisure time. They conclude that social capital is stronger when virtual networks overlap face-to-face networks thereby facilitating network density and the flow of information.

Henderson and Gilding (2004) studied the development of trust in the context of online friendships. This study was based on semi-structured interviews with 17 Internet users to explore the foundations of trust in online 
friendship. There were four main areas of trust identified: Reputation, performance, pre-commitment and situational factors. The majority of the respondents did not separate their online and offline worlds but used sharing information from the broader context as a way to establish their reputation to build trust. Communication, self-disclosure and risk-taking as components of performance were essential for building online trust and were framed as possibly easier to perform when building trust in online relationships. Pre-commitment facilitated hyper personal communication and online trust. Pre-commitment occurred when respondents purposefully changed the context of their own actions through self-disclosure, promoting reciprocity, therefore making it easier to take the risk of developing an online friendship. Finally they found that broad situational factors in Western societies promote active trust and personal networks:"Respondents had no doubt that the bet on an online friendship was not a frivolous one".

Shan, Kwak \& Holbert (2001) explored Internet use and the production of social capital in a study where interpersonal trust was defined as a criterion variable for social capital. It was identified that Internet use, was weakly related to interpersonal trust. When they controlled for a wide range of demographic and contextual variables, Internet use retained meaningful associations with interpersonal trust. In regards to trusting attitude toward other people, those who were older, female, more affluent, and members of a racial majority were more likely to be trusting of others. When different types of Internet usage patterns were simultaneously considered there was not a significant association with any of the criterion variables thus highlighting the importance of considering contextual factors. When they differentiated based on people's use of the Internet they found that when the Internet was used for social recreation (chat rooms and game playing) it was consistently and negatively related to trust in other people. However when people used the Internet for information exchange it was found to have a positive impact on trust in other people. This study is unique in that instead of just looking at total time spent on the Internet, this exploratory analysis identified that the amount of time is less important than what they are doing when they connect online and that the production of social capital (interpersonal trust) is dependent on the motives individuals bring to their use of the web.

Social media has no effect on trust: We have found two studies claiming that social media/internet has no effect on trust; Uslaner (2004) and Jennings \& Zeitner (2003). Uslaner, like many other studies, uses the Pew Center's survey on Internet and Internet use. According to Uslaner Internet users tend to have a slightly wider social life than non-users, but since their Internet communications are with people they know, Internet users are not more trusting than others. However, Internet users are not less trusting than others either. This result fits Uslaner's general idea of trust, as discussed earlier.

A problem in most studies (so also in Uslaner, 2004) is that they use cross-sectional data. This means that they do not have any over-time observations, which also makes the question of causality difficult. Cross-sectional data can tell us about correlation, but cannot identify whether Internet use leads to trust, or if it is the trusting that use the Internet. Jennings \& Zeitner (2003), however, use a panel study done 1982 and 1997 that builds on a national sample of the high school class of 1965. This means that the respondents were to answer the survey before Internet era (1982) and at a time after Internet was introduced. The measurements on social trust are an index that uses the three standard questions (in short): Most people can be trusted, people try to be helpful, and people try to take advantage of you. Jennings \& Zeitner found that gaining access to the Internet between 1982 and 1997 was associated with a positive contribution to several widely used indicators of civic engagement. However, social trust was not one of them. Social trust showed no significant change between 1982 and 1997 so social trust is not associated with Internet use. Thus, Internet users and nonusers show no significant difference when it comes to social trust. 


\section{Conclusions}

Considering how much attention Putnam's work on social capital has drawn since "Making Democracy Work" in 1993, we were surprised that there has not been more research on the issue of social media and social trust. All together we found ten articles with original research on the issue. Of these ten articles, eight found some kind of positive relation between social media and trust. These articles begin to explore the relationship between trust and social media however the depth and reciprocity of these relationships has not been well developed. There are also other reflections to make. One interesting result is the one Monforti\&Marichal propose, namely that the Internet can work differently for different ethnicities. In their case there was a positive relationship between trust and the Internet for African Americans, but not for other ethnicities. According to the authors the explanation might be that Internet can free African Americans from a social stigma that persists even for African Americans in high-status positions. This raises the question if the Internet can reduce barriers and level the opportunity for marginalized groups to build trust.

Another reflection is that most of the studies use cross-sectional data. When cross-sectional data is used there is a problem with causality - it is difficult to know if it is the trusting that use internet more or if it is the internet use that leads to trust? Only one study uses longitudinal data, and this study finds no relationship between Internet use and trust. Only one study uses a qualitative method and it found a positive relationship between social trust and Internet use and indicated that relationship development on the web was not viewed less seriously than "live" relationship.

A third reflection is that how the Internet is used is of importance. One study found a positive relationship when it was used for information but a negative one when it is used for recreation. Another study found a positive relationship between social media and trust when mediated by the choice to use social media to build or maintain social connections and that perceived information overload was inversely associated with interpersonal trust. A third study found positive results when social media use is combined with face-to-face interaction.

The conclusion is that we need additional research on a more disaggregated level using other methods and data rather than just quantitative analysis on cross-sectional data. We need to know if there is any difference between who uses social media, for example between different ethnic groups, and if how the internet is used really matters. Furthermore, we need to know more about causality: is it the trusting that use the Internet or is it Internet use that creates trust.

\section{References:}

Alex-Brown K. (2011). "Blogging and micro-blogging inside a large, high-tech corporation: Inside a large, high-tech corporation: Impacts on the information of organizational social capital”, Unpublished doctoral dissertation, Texas Tech University, Lubbock, TX.

Anderson J. and Rainie L. (2014). “The Future of the Internet: Net Threats”, Pew Research Center's Internet and American Life Project, available online at: http://www.pewinternet.org.

Beaudoin C. E. (2008). "Explaining the relationship between internet use and interpersonal trust: Taking into account motivation and information overload”, Journal of Computer-Mediated Communication, Vol. 13, No. 3, pp. 550-568.

Berger C. R. and Calabrese R. J. (1975). "Some explorations in initial interaction and beyond: Toward a developmental theory of interpersonal communication”, Human Communication Research, Vol. 1, No. 2, pp. 99-112.

Best S. J. and Krueger B. S. (2006). “Online interactions and social capital distinguishing between new and existing ties”, Social Science Computer Review, Vol. 24, No. 4, pp. 395-410.

Bian J., Liu Y., Zhou D., Agichtein E. and Zha H. (2009). "Learning to recognize reliable users and content in social media with coupled mutual reinforcement”, in: Proceedings of the 18th International Conference on World Wide Web, ACM, pp. 51-60. 
Blanchard A. and Horan T. (1998). "Virtual communities and social capital”, Social Science Computer Review, Vol. 16, No. 3, pp. 293-307.

Cabral J. (2011). “Is generation Y addicted to social media?”, The Elon Journal of Undergraduate Research in Communications, Vol. 2, No. 1.

Duggan M. and Smith A. (2013). "Social media update 2013”, Pew Internet and American Life Project.

DuBois T., Golbeck J. and Srinivasan A. (2011). "Predicting trust and distrust in social networks”, in: 2011 IEEE International Conference on Privacy, Security, Risk, and Trust, and IEEE International Conference on Social Computing.

Ellison N., Steinfield C. and Lampe C. (2007). “The benefits of Facebook 'friends': Exploring the relationship between college students' use of online social networks and social capital”, Journal of Computer-Mediated Communication, Vol. 12, No. 3.

Henderson S. and Gilding M. (2004). “'I’ve never clicked this much with anyone in my life': Trust and hyper personal communication in online friendships”, New Media \& Society, Vol. 6, No. 4, pp. 487-506.

Jennings M. K. and Zeitner V. (2003). “Internet use and civic engagement: A longitudinal analysis”, The Public Opinion Quarterly, Vol. 67, No. 3, pp. 311-334.

Joinson A. N. (2008). “'Looking at’, ‘Looking up’ or ‘Keeping up with’ People? Motives and Uses of Facebook”, in: CHI 2008 Proceedings: Online Social Networks, Florence, Italy, April 5-10, 2008, pp. 1027-1036.

Kitchenham B. (2004). “Procedures for performing systematic reviews”, Keele University Technical Report TR/SE-0401.

Kitchenham B., Pearl Brereton O., Budgen D., Turner M., Bailey J. and Linkman S. (2009). "Systematic literature reviews in software engineering - A systematic literature review”, Information and Software Technology, Vol. 51, No. 1, pp. 7-15.

Kline J. and Barker T. (2012). "Negotiating professional consciousness in technical communication: A community of practice approach”, Technical Communication, Vol. 59, No. 1, pp. 32-48.

Knack S. and Keefer P. (1997). "Does social capital have an economic payoff? A cross-country investigation”, The Quarterly journal of Economics, Vol. 112, No. 4, pp. 1251-1288.

Liss J. (2011). “Negotiating the marcellus: The role of information in building trust in extractive deals”, Negotiation Journal, Oct 2011, Vol. 27, No. 4, pp. 419-446.

Monforti J. L. and Marichal J. (2014). "The role of digital skills in the formation of generalized trust among Latinos and African Americans in the United States”, Social Science Computer Review, Vol. 32, No. 1, pp. 3-17.

Norris P. (1996). “Does television erode social capital? A reply to Putnam”, PS: Political Science \& Politics, Vol. 29, No. 3, pp. 474-480.

Oblinger D. and Oblinger J. (2005). “Is it age or IT: First steps toward understanding the net generation”, in: Oblinger \& Oblinger (Eds.), Educating the Net Generation, Vol. 2, Nos. 1-2, p. 20.

Putnam R. D. (2000). Bowling Alone: The Collapse and Revival of American Community, New York: Touchstone.

Putnam R. D. (1993). Making Democracy Work: Civic Traditions in Modern Italy, Princeton, New Jersey: Princeton University Press.

Rheingold H. (1993). The Virtual Community: Homesteading on the Electronic Frontier, MIT Press.

Rothstein B. (2003). Socialafällorochtillitens Problem, Stockholm: SNS Förlag.

Shah D. V., Kwak N. and Holbert R. L. (2001). “'Connecting'” and 'disconnecting' with civic life: Patterns of Internet use and the production of social capital”, Political Communication, Vol. 18, No. 2, pp. 141-162.

Tidwell L. C. and Walther J. B. (2002). "Computermediated communication effects on disclosure, impressions, and interpersonal evaluations: Getting to know one another a bit at a time”, Human Communication Research, Vol. 28, No. 3, pp. 317-348.

Uslaner E. M. (1998). “Social capital, television, and the 'mean world': Trust, optimism, and civic participation”, Political Psychology, Vol. 19, No. 3, pp. 441-467.

Uslaner E. M. (2004). “Trust, civic engagement, and the internet”, Political Communication, Vol. 21, pp. 223-242.

Uslaner E. M. (2002). The Moral Foundation of Trust, New York: Cambridge University Press.

Valenzuela S., Park N. and Kee K. F. (2009). “Is there social capital in a social network site? Facebook use and college students’ life satisfaction, trust, and participation1”, Journal of Computer-Mediated Communication, Vol. 14, No. 4, pp. 875-901.

Zak P. J. and Knack S. (2001). “Trust and growth”, The Economic Journal, Vol. 111, No. 470, pp. 295-321. 